\title{
Comparative analysis of antioxidant and antiproliferative activities of Rhodomyrtus tomentosa extracts prepared with various solvents
}

\begin{abstract}
Rhodomyrtus tomentosa (Aiton) Hassk. has a wide spectrum of pharmacological effects and has been used to treat wounds, colic diarrhoea, heartburns, abscesses and gynaecopathy. The potential antiproliferative activities of $\mathrm{R}$. tomentosa extracts from different solvents were evaluated in vitro on HepG2, MCF-7 and HT 29 cell lines while antioxidant activity was monitored by radical scavenging assay (DPPH), copper reducing antioxidant capacity (CUPRAC) and $\beta$-carotene bleaching assay. Extracts from R. tomentosa show the viability of the cells in concentration-dependent manner. According to the IC50 obtained, the ethyl acetate extracts showed significant antiproliferative activity on HepG2 (IC50 $11.47 \pm 0.280$ $\mu \mathrm{g} / \mathrm{mL}$ ), MCF-7 (IC50 $2.68 \pm 0.529 \mu \mathrm{g} / \mathrm{mL}$ ) and HT 29 (IC50 $16.18 \pm 0.538 \mu \mathrm{g} / \mathrm{mL}$ ) after 72 $\mathrm{h}$ of treatment. Bioassay guided fractionation of the ethyl acetate extract led to the isolation of lupeol. Methanol extracts show significant antioxidant activities in DPPH (EC50 110.25 \pm $0.005 \mu \mathrm{g} / \mathrm{ml}$ ), CUPRAC (EC50 $53.84 \pm 0.004$ ) and $\beta$-carotene bleaching (EC50 $58.62 \pm$ $0.001)$ due to the presence of high total flavonoid and total phenolic content which were $110.822 \pm 0.017 \mathrm{mg}$ butylated hydroxytoluene $(\mathrm{BHT}) / \mathrm{g}$ and $190.467 \pm 0.009 \mathrm{mg}$ gallic acid (GAE)/g respectively. Taken together, the results extracts show the R. tomentosa as a potential source of antioxidant and antiproliferative efficacy.
\end{abstract}

Keyword: Antioxidant; Antiproliferative; Cytotoxicity; Kemunting; Lupeol; Rhodomyrtustomentosa 